\title{
ANTIMICROBIAL ACTIVITY OF ESSENTIAL OILS AGAINST VANCOMYCIN-RESISTANT ENTEROCOCCI (VRE) AND ESCHERICHIA COLI O157:H7 IN FETA SOFT CHEESE AND MINCED BEEF MEAT
}

\author{
Samy Selim
}

Microbiology Section, Botany Department, Faculty of Science, Suez Canal University, 41522, Ismailia, Egypt.

Submitted: October 14, 2009; Returned to authors for corrections: April 23, 2010; Approved: June 21, 2010.

\begin{abstract}
Eleven essential oils (EOs) were evaluated for their antibacterial properties, against Vancomycin-Resistant Enterococci (VRE) and E. coli O157:H7. EOs were introduced into Brain Heart Infusion agar (BHI) $(15 \mathrm{ml})$ at a concentration of 0.25 to $2 \%(\mathrm{vol} / \mathrm{vol})$ to determine the minimum inhibitory concentration (MIC) and minimum bactericidal concentration (MBC) for each pathogen evaluated. Results showed that the most active essential oils against bacteria tested were thyme oil, with $\mathrm{MIC}_{90}$ and $\mathrm{MBC}_{90}$ for the VRA strains of $0.25 \%$ and $0.5 \%$, respectively. Eucalyptus, juniper and clove oils were the least potent agent, with $\mathrm{MIC}_{90}$ and $\mathrm{MBC}_{90}$ of $2 \%$. Furthermore, the inhibitory effect of these EO were evaluated against VRE and E. coli $\mathrm{O} 157: \mathrm{H} 7$, experimentally inoculated $\left(10^{3} \mathrm{cfu} / \mathrm{g}\right)$ in Feta soft cheese and minced beef meat, which was mixed with different concentrations $(0.1 \%, 0.5 \%$ and $1 \%)$ of the EO and stored at $7{ }^{\circ} \mathrm{C}$ for 14 days. Out of eucalyptus, juniper, mint, rosemary, sage, clove and thyme oils tested against target bacteria sage and thyme showed the best results. Clove and mint did not show any effect on VRE and E. coli O157:H7 in both kinds of studied foods. The addition of thyme oil at concentrations of 0.5 and $1 \%$ caused best significant reduction in the growth rate of VRE and E. coli $\mathrm{O} 157: \mathrm{H} 7$ in cheese and meat at $7{ }^{\circ} \mathrm{C}$. It is concluded that selected plant EOs can act as potent inhibitors of both microorganisms in a food product. The results revealed the potential of thyme oil as a natural preservative in feta soft cheese and minced beef meat against VRE and E. coli O157:H7 contamination.
\end{abstract}

Key words: Essential oils, VRE, E. coli O157:H7, Feta soft cheese, minced beef meat.

\section{INTRODUCTION}

Enterococci are important Gram-positive bacteria of food safety and public health concern. Among the predominant bacteria involved in these pathogens, enterococci are a leading cause of gastroenteritis resulting from the consumption of contaminated food (19). Enterrococci occur in foods because the lactic acid enterococcus bacteria, particularly E. faecalis and E. faecium, have a long history of use by food industry as starter cultures in the production of traditional fermented food and cheese. Enterococci of food-borne origin have not been conclusively identified as direct causes of clinical infections; however, the consumption of food carrying antibiotic-resistant bacterial populations is a possible route of transfer and could result in either colonization or transfer of resistance determinants to host-adapted strains $(18, \quad 19,33)$.

\footnotetext{
*Corresponding Author. Mailing address: Microbiology Section, Botany Department, Faculty of Science, Suez Canal University, 41522, Ismailia, Egypt Email: s.selim@scuegypt.edu.eg
} 
Antimicrobial-resistant enterococcal strains have been isolated from meat products, dairy products, fresh produce and the poultry production environment (11). Among antibiotic resistant enterococci, the emergence, selection and spread of enterococci resistant to glycopeptide antibiotics vancomycin in a hospital environment is of particular concern, because glycopeptide antibiotics often represent the last therapeutic option in the treatment of infections caused by enterococci (11, 18. 19). E. coli $\mathrm{O} 157: \mathrm{H} 7$ is another concern to public health on a global scale (20) and is found in a wide variety of foodstuffs including meat and meat products, milk, yogurt, water, salad vegetables, fruits, fruit juices and cider $(2,20)$. Pasteurization and cooking are adequate methods of ensuring that viable cells are eliminated, but heat treatment is not desirable for all foods and cross-contamination cannot always be prevented. Controlling the numbers and growth of E. coli O157:H7 therefore remains an important objective for sectors of the food production industry (22).

The demand for safe foods, coupled with the preference by consumers for foods free of synthetic additives, has increased the interest for natural preservatives in recent years (27). Great emphasis has recently been focused on the utilization of spices and their EOs as natural agents for food preservation (1). Most studies have evaluated the antimicrobial activity of naturally occurring botanicals on in vitro experiments. In vitro studies have demonstrated antibacterial activity of EOs against Listeria monocytogenes, Salmonella, E. coli 0157:H7, Shigella dysenteria, Bacillus cereus and Staphylococcus aureus (3, 8, $10,12,13,16,22)$. However, the information of their effect in actual food systems is still insufficient. Higher concentrations are needed to achieve the same effects in food systems (29). The greater availability of nutrients in foods compared to laboratory media may enable bacteria to repair damaged cells faster (14). The studies on actual foods show that some botanicals have the potential to be effective biopreservatives, although product development to optimize food functionality and flavor will be challenging and more studies are needed on the topic of botanical applications to fully understand how best to optimize their use and provide the fundamentals needed by the food industry (10). The future of naturally occurring antimicrobials seems promising; as new preservation methods are rapidly incorporated in a variety of foods once their effectiveness and safety have been well documented. The effectiveness of essential oil application in actual food systems is the result of multiple factor associations such as the food composition or the storage temperatures $(4,6,14,26,31,32)$. The presence of surfactants and organic substances that interact with active sites of the antimicrobial substances also plays an important role (16).

It has long been acknowledged that some EOs exhibit antimicrobial properties. Recent studies have shown that EO of oregano, thyme, bay and clove are among the most active in this respect against strains of E. coli (4, 9, 16, 30). Moreira et al. (2005) reported in an in vitro study that the essential oils from clove and tea tree had inhibitory effects on E. coli O157:H7 using the agar diffusion method. But the information of EOs effect on VRE is still insufficient. Just the bacteriostatic and bactericidal activities of oils against VRE are showed VRE strains were less susceptible to tea tree, lavender, mint and thyme oils (23). The purpose of this study was to select from EOs those with the most pronounced antibacterial properties, to determine at which concentration they were bacteriostatic and bactericidal to VRE and E. coli $\mathrm{O} 157: \mathrm{H} 7$. Also the aim of this work was to evaluate the effectiveness of EOs to control VRE and E. coli $\mathrm{O} 157: \mathrm{H} 7$ on actual food systems (feta soft cheese and minced cooked beef) exposed to abusive refrigeration ( 7 $\left.{ }^{\circ} \mathrm{C}\right)$.

\section{MATERIALS AND METHODS}

\section{Plant samples}

Plant target species are summarized in Table 1. For this study fresh plant material was used. The plants were collected during the vegetation period, botanically identified and immediately processed. Besides well known species with documented antibacterial activity in direct contact assays, several species with unknown antibacterial effect were selected. 
Table 1. List of plant species tested

\begin{tabular}{lccc}
\hline Plant species & Family & Common name & Plant part \\
\hline Ambrosia maritime & Asteraceae & Ragweed & Arial part \\
Eucalyptus globulus & Myrtaceae & Eucalyptus & Leaves \\
Juniperus communis & Cupressaceae & Common Juniper & Leaves \\
Mentha longifolia & Lamiaceae & Mint & Leaves \\
Mentha piperita & Lamiaceae & Peppermint & Leaves \\
Myristica fragrans & Myristicaceae & Nutmeg & Seeds \\
Piper nigrum & Piperaceae & Black Pepper & Seeds \\
Rosmarinus officinalis & Lamiaceae & Rosemary & Leaves \\
Salvia officinalis & Lamiaceae & Sage & Leaves \\
Syzygium aromaticum & Myrtaceae & Clove & Seeds \\
Thymus vulgaris & Lamiaceae & Thyme & Arial part \\
\hline
\end{tabular}

\section{Preparation of EO}

Essential oils were obtained by Clevenger hydrodistillation method. The plant material (about $300 \mathrm{~g}$ ), was cut into small pieces, and placed in a flask (4 1) together with doubly distilled water (1.5 1). The mixture was boiled for $3 \mathrm{~h}$, collected EO were dried with anhydrous sodium sulphate and kept at $-18^{\circ} \mathrm{C}$ until its use.

\section{Maintenance and preparation of cultures}

VRE was isolated from food samples on Slanetz Bartley (SB) Agar (Oxoid, England) plates and incubated at $35^{\circ} \mathrm{C}$ for 4 $\mathrm{h}$ and then at $44{ }^{\circ} \mathrm{C}$ for $20 \mathrm{~h}$. Deep red of maroon colonies were accepted as enterococci. The second step of the study was held using the same food samples for confirmation of VRE. A loopful of this isolates was streaked on SB agar supplemented with vancomycin (Oxoid, England) and it was incubated at 37 ${ }^{\circ} \mathrm{C}$ for $24 \mathrm{~h}$. Round grey or pale brown colonies surrounded with black zones were accepted as VRE colonies. Cultures of E. coli $\mathrm{O} 157: \mathrm{H} 7$ strain isolated from bovine faeces were maintained on tryptone soya broth agar (TSBA) slants at $4^{\circ} \mathrm{C}$. The agar slants were made by the addition of $1 \%(\mathrm{w} / \mathrm{v})$ bacteriological agar Nr. 1 (Oxoid, UK) to TSBA (Oxoid). Inocula were prepared by $16 \mathrm{~h}$ culture in Mueller-Hinton Broth (MHB; Oxoid) at $37^{\circ} \mathrm{C}$. The test organisms included 13 of VRE and 16 of E. coli O157:H7 of non replicate strains. All of the VRE isolates were identified as E. faecium.

\section{EO dispersion in the culture medium}

First, 11 suspensions were prepared with EOs. The oils were dispersed at room temperature for 2 min using a homogenizator at $20,000 \mathrm{rpm}$ in a sterile $10 \%$ (wt/vol) modified starch solution to obtain a colloidal suspension $(10 \%$, wt/vol) (24). The presence of modified starch improved oil dispersion and improve the antimicrobial properties (4). The starch-oil suspensions were added in molten BHI agar (Difco Laboratories, USA) maintained at $62 \pm 1{ }^{\circ} \mathrm{C}$ and strongly mixed for $2 \mathrm{~min}$ using a vortex. Six (6) final concentrations of oils $(0.25$ to $2 \%(\mathrm{vol} / \mathrm{vol}))$ were obtained by adding various volumes from the $10 \%(\mathrm{wt} / \mathrm{vol})$ suspension. The molten agar $(15 \mathrm{ml})$ containing essential oils were poured into sterile petri plates and left to solidify.

\section{Determination of MIC and MBC}

The MIC of the tested EO was determined using an agar dilution method (24). Briefly, Petri plates of BHI agar containing various concentrations of EOs were inoculated with each bacterial strain evaluated. Each working culture $\left(2 \times 10^{7} \mathrm{cfu} / \mathrm{ml}\right)$ was diluted to obtain $10^{-4}$ and $10^{-5}$ in peptone water $(0.1 \% \mathrm{wt} / \mathrm{vol})$ and $40 \mu \mathrm{L}$ of each diluted culture was individually spread on the surface of the solidified agar plates. The positive control consisted of BHI agar without essential oil, inoculated with the diluted medium culture. Uninoculated plates containing essential oils served as negative control. Test and control plates were then incubated at $35 \pm 1{ }^{\circ} \mathrm{C}$. Plates were evaluated for the presence or the absence of colonies after $48 \mathrm{~h}$ of incubation. For each treatment, the absence of colonies on all plates tested was considered as an inhibitory effect. The lowest concentration of essential oil required to completely 
inhibit the growth of the tested microorganism was designated as the MIC. MBC is usually an extension from the MIC, where the organisms are quantitatively indicate the minimum concentration was no viable organism appears in the culture.

\section{Inhibitory effect of the potent EOs against VRE and $E$. coli 0157:H7 inoculated in Feta soft cheese}

Feta soft cheese was purchased from local supermarket, the packaging showed the presence of no artificial preservatives. Initial experiments of inoculating TSA plates with cheese diluted 1 in 10 with PBS and incubating at $37^{\circ} \mathrm{C}$ for $48 \mathrm{~h}$ showed no microbial contamination of either product. The procedure was based on that of Smith-Palmer et al., (2001), $10 \mathrm{~g}$ of cheese was added to $90 \mathrm{ml}$ of phosphate buffered saline (PBS) (Sigma-Aldrich, UK) in stomacher bags and homogenized for $2 \mathrm{~min}$ in a stomacher (Seward Medical, London, UK). Potent EOs of (EOs had antimicrobial activity against studied strains less than $1 \% \mathrm{v} / \mathrm{v}$ concentration) eucalyptus, juniper, mint, rosemary, sage, clove and thyme were added to the cheese mixture to achieve final concentrations of $0.1,0.5$ and $1 \%$. The controls contained PBS but no EOs.

The cheese mixture was inoculated with $100 \mathrm{ml}$ of coldadapted VRE and E. coli O157:H7 cultures that had been prepared by growing for 24 hours in 10ml TSB in an orbital incubator $(100 \mathrm{rpm})$. The inoculums was mixed thoroughly with the cheese mixture by gently squeezing the bags by hand and the concentration of both strains in the cheese determined at $0,1,2,3,4,7,10$ and 14 days storage at $7^{\circ} \mathrm{C}$ using the serial dilution and spread plate technique (17). The counts were taken on SB agar supplemented with vancomycin for VRE and TSBA medium plates for E. coli $\mathrm{O} 157: \mathrm{H} 7$ by surface plating the appropriate dilutions of the samples aseptically in duplicate. Prior to removing samples, the contents of the bags were mixed by gently squeezing the bags by hand. Three individual replicates of each experiment were performed, in all cases.

Inhibitory effect of the potent EOs against VRE and $E$. coli

\section{7:H7 inoculated in minced beef meat}

The procedure described by Careaga et al. (2003) was followed with slight modifications. Post-rigor lean beef muscles were obtained from a slaughter house in Egypt. Each piece was immersed in boiling water for $5 \mathrm{~min}$, in order to reduce the number of the microorganisms attached to the surface of the beef muscle. The cooked surface of the muscle was eliminated with sterile knives under aseptic conditions. The pieces of meat prepared as above were minced in a sterile grinder, and portions of $250 \pm 0.1 \mathrm{~g}$ were put in high-density polyethylene bags. Half of the meat samples were inoculated with $10^{3} \mathrm{cfu}$ of VRE/g of meat, and the remaining half with $10^{3}$ cfu of E. coli $0157: \mathrm{H} 7 / \mathrm{g}$ of meat. Prior to the inoculation of the meat, the samples were added different concentrations of EOs. For testing the survival of VRE and E. coli O157:H7 species the concentrations of the potent EOs used (eucalyptus, juniper, mint, rosemary, sage, clove and thyme) were $0.1,0.5$ and $1 \%(\mathrm{v} / \mathrm{w})$. The samples were homogenized using a Stomacher 400 Seward (London, England) at normal speed for $5 \mathrm{~min}$. All the bags containing the samples of meat were refrigerated $\left(7^{\circ} \mathrm{C}\right)$ and examined after $0,1,2,3,4,7,10$ and 14 of storage for each microorganism. The untreated controls were added sterile water (instead of EO), inoculated with the test bacteria, and stored under the same conditions as the other samples.

After preparing and inoculating beef samples at day 0 and following incubation at $7^{\circ} \mathrm{C}$, randomly selected bags containing meat were examined for VRE and E. coli O157:H7. The VRE and E. coli $\mathrm{O} 157: \mathrm{H} 7$ isolation was done by adding $25 \mathrm{~g}$ of meat to a plastic bag containing $225 \mathrm{ml}$ of $1 \%$ peptone water. The samples were homogenized for 1 min using the Stomacher, and incubated at $35^{\circ} \mathrm{C}$ for $24 \mathrm{~h}$. From this pre-enrichment (for the resuscitation of possible injured living cells), $1 \mathrm{ml}$ was added to $9 \mathrm{ml}$ of peptone broth and incubated at $35^{\circ} \mathrm{C}$ for $24 \mathrm{~h}$. The counts were taken on SB agar supplemented with vancomycin for VRE and TSBA medium plates for E. coli O157:H7 by surface plating the appropriate dilutions of the samples aseptically in duplicate. Three individual replicates of each experiment were performed, in all cases. 


\section{Statistical analysis}

The variations between experiments were estimated by standard deviations and statistical significance of changes was estimated by student's t-test. Only the probability $\mathrm{P} \leq 0.001$ was regarded as indicative of statistical significance.

\section{RESULTS}

MIC and MBC activities of EO against VRE and E. coli 0157:H7

The averages of bacteriostatic and bactericidal activities of the eleven EO against the 13 strains of VRE and 16 of E. coli O157:H7 are shown in the Table 2. Of the 11 EO tested, eucalyptus, juniper, mint, rosemary, sage, clove and thyme seem to be the most efficient essential oils against the VRE and E. coli O157:H7. Ragweed, peppermint, nutmeg and black Pepper oils were showed no activity against VRE and E. coli O157:H7 strains. Thyme oil was the most potent of the oils, with $\mathrm{MIC}_{90}$ and $\mathrm{MBC}_{90}$ for the VRA strains of $0.25 \%$ and $0.5 \%$, respectively. Eucalyptus, juniper and clove oils were the least potent agent, with $\mathrm{MIC}_{90}$ and $\mathrm{MBC}_{90}$ of $2 \%$. Depending on the oil, the E. coli $\mathrm{O} 157: \mathrm{H} 7$ strains were up to four-fold less susceptible than the VRE isolates to rosemary, sage, clove and thyme oils, the activities of which were equivalent.

\section{Effect of EO on food samples}

In the present study, we report for the first time effect of EO on VRE in food systems. Out of eucalyptus, juniper, mint, rosemary, sage, clove and thyme oils tested against target bacteria, sage and thyme showed the best results. Clove and mint oils did not show any effect on VRE and E. coli O157:H7 in both kinds of studied foods. Figures 1 and 2 shows the evolution of VRE and E. coli $\mathrm{O} 157: \mathrm{H} 7$ populations on two kinds of foods treated with different EO concentrations (Data of non significant effect of oils not published). During storage, both VRE and E. coli O157:H7 counts were similar. This would indicate that the populations of $E$. coli $0157: \mathrm{H} 7$ predominated in and that no VRE presented a differential rate of growth under the experimental storage conditions. The initial E. coli $\mathrm{O} 157: \mathrm{H} 7$ counts were not significantly $(P<0.01)$ different in control samples and samples treated with sage and thyme essential oil at $0.1 \%$. The use of essential oil at 0.5 and $1 \%$, however, resulted in a significant $2-\log$ cycle reduction in the VRE and E. coli O157:H7 counts, exerting a bactericidal effect for sage and thyme oils.

Table 2. The averages of MICs and MBCs values of EOs against VRE ( $\mathrm{n}=13)$ and E. coli O157:H7 (n = 16) strains

\begin{tabular}{|c|c|c|c|c|c|c|c|}
\hline \multirow[b]{2}{*}{ Oil } & \multirow[b]{2}{*}{ Bacterium } & \multicolumn{2}{|c|}{$\operatorname{MIC}(\% \mathrm{v} / \mathrm{v})$} & \multicolumn{2}{|c|}{$\operatorname{MBC}(\% \mathrm{v} / \mathrm{v})$} & \multirow[b]{2}{*}{$\mathrm{MBC}_{90}$} & \multirow[b]{2}{*}{ Range } \\
\hline & & $\mathrm{MIC}_{50}$ & $\mathrm{MIC}_{90}$ & Range & $\mathrm{MBC}_{50}$ & & \\
\hline \multirow{2}{*}{ Ragweeds } & VRE & $* \mathrm{NA}$ & NA & NA & NA & NA & NA \\
\hline & E. coli $\mathrm{O} 157: \mathrm{H} 7$ & & & & & NA & NA \\
\hline \multirow[t]{2}{*}{ Eucalyptus } & VRE & 0.5 & 1 & $>2$ & 0.5 & 1 & $>2$ \\
\hline & E. coli $\mathrm{O} 157: \mathrm{H} 7$ & & & $>2$ & & & $>2$ \\
\hline \multirow[t]{2}{*}{ Juniper } & VRE & 0.5 & 1 & $>2$ & 0.5 & 1 & $>2$ \\
\hline & E. coli $\mathrm{O} 157: \mathrm{H} 7$ & & & $>2$ & & & $>2$ \\
\hline \multirow[t]{2}{*}{ Mint } & VRE & $>2.0$ & $>2.0$ & $>2$ & $>2$ & $>2$ & $>2$ \\
\hline & E. coli $\mathrm{O} 157: \mathrm{H} 7$ & & & $0.5-1$ & & & $0.5-1$ \\
\hline \multirow[t]{2}{*}{ Peppermint } & VRE & NA & NA & NA & NA & NA & NA \\
\hline & E. coli $\mathrm{O} 157: \mathrm{H} 7$ & & & NA & & & NA \\
\hline \multirow{2}{*}{ Nutmeg } & VRE & NA & NA & NA & NA & NA & NA \\
\hline & E. coli $\mathrm{O} 157: \mathrm{H} 7$ & & & NA & & & NA \\
\hline \multirow{2}{*}{ Black Pepper } & VRE & NA & NA & NA & NA & NA & NA \\
\hline & E. coli $\mathrm{O} 157: \mathrm{H} 7$ & & & NA & & & NA \\
\hline \multirow[t]{2}{*}{ Rosemary } & VRE & 0.25 & 0.25 & $0.25-1$ & 0.25 & 0.25 & $0.5-1$ \\
\hline & E. coli $\mathrm{O} 157: \mathrm{H} 7$ & & & $0.25-0.5$ & & & $0.25-0.5$ \\
\hline \multirow[t]{2}{*}{ Sage } & VRE & 0.25 & 0.25 & $0.25-0.5$ & 0.25 & 0.25 & $0.25-0.5$ \\
\hline & E. coli $\mathrm{O} 157: \mathrm{H} 7$ & & & $>2$ & & & $>2$ \\
\hline \multirow{2}{*}{ Clove } & VRE & $>2$ & $>2$ & $>2$ & $>2$ & $>2$ & $>2$ \\
\hline & E. coli $\mathrm{O} 157: \mathrm{H} 7$ & & & $>2$ & & & $>2$ \\
\hline \multirow[t]{2}{*}{ Thyme } & VRE & 0.25 & 0.25 & 0.25 & 0.25 & 0.5 & 0.5 \\
\hline & E. coli $\mathrm{O} 157: \mathrm{H} 7$ & & & 0.5 & & & 0.5 \\
\hline
\end{tabular}


The addition of thyme oil at concentrations of 0.5 and $1 \%$ caused a significant reduction in the growth rate of VRE and $E$. coli $\mathrm{O} 157: \mathrm{H} 7$ in cheese at $7{ }^{\circ} \mathrm{C}$ (Fig. 1a and 1b). At a thyme oil concentration of $0.5 \%$, the treated samples showed a decrease in VRE a population of nearly $1 \log 10 \mathrm{cfu} / \mathrm{g}$ compared to the control samples after storage at $7{ }^{\circ} \mathrm{C}$ for 1,2 and 3 days, although on subsequent holding, the difference between the two groups was not significant (Fig. 1). Significant differences were observed between the two groups at $7{ }^{\circ} \mathrm{C}$ as well, but the maximum difference was recorded after 7 days $(P<0.01)$. Increasing the concentration of sage oil to $1 \%$ enhanced its inhibitory action on E. coli O157:H7.

Meat samples treated with clove oil showed fewer VRE counts than the corresponding control samples on holding these at $7{ }^{\circ} \mathrm{C}$ (Fig.2a and 2b). The addition of $0.5 \%$ thyme oil restricted the growth of the initial E. coli $\mathrm{O} 157: \mathrm{H} 7$ population from $7.7 \times 10^{3} \mathrm{cfu} / \mathrm{g}$ to $1.8 \times 10^{5} \mathrm{cfu} / \mathrm{g}$ after 1 day's storage at $7^{0} \mathrm{C}$, while the corresponding increase in the control meat was from $8.7 \times 10^{3} \mathrm{cfu} / \mathrm{g}$ to $2.6 \times 10^{6} \mathrm{cfu} / \mathrm{g}(\mathrm{P} \leq 0.01)$.

Treatment with $0.5 \%$ thyme oil revealed significant effects on VRE after 3, 6 and 9 days' storage. A higher concentration of thyme oil (1\%) improved the ant E. coli $\mathrm{O} 157: \mathrm{H} 7$ action in meat. As a result, the initial E. coli $\mathrm{O} 157: \mathrm{H} 7$ population of $10^{4}$ $\mathrm{cfu} / \mathrm{g}$ showed a marginal fall in the treated meat at day 0 to $3.9 \times 10^{3} \mathrm{cfu} / \mathrm{g}$. The counts in the treated group after 5 days were also significantly lower than in the control group $(\mathrm{P} \leq 0.01)$. On storage of meat samples at $7{ }^{\circ} \mathrm{C}$, significantly lower levels of cells were recorded in treated meat throughout the experiment.
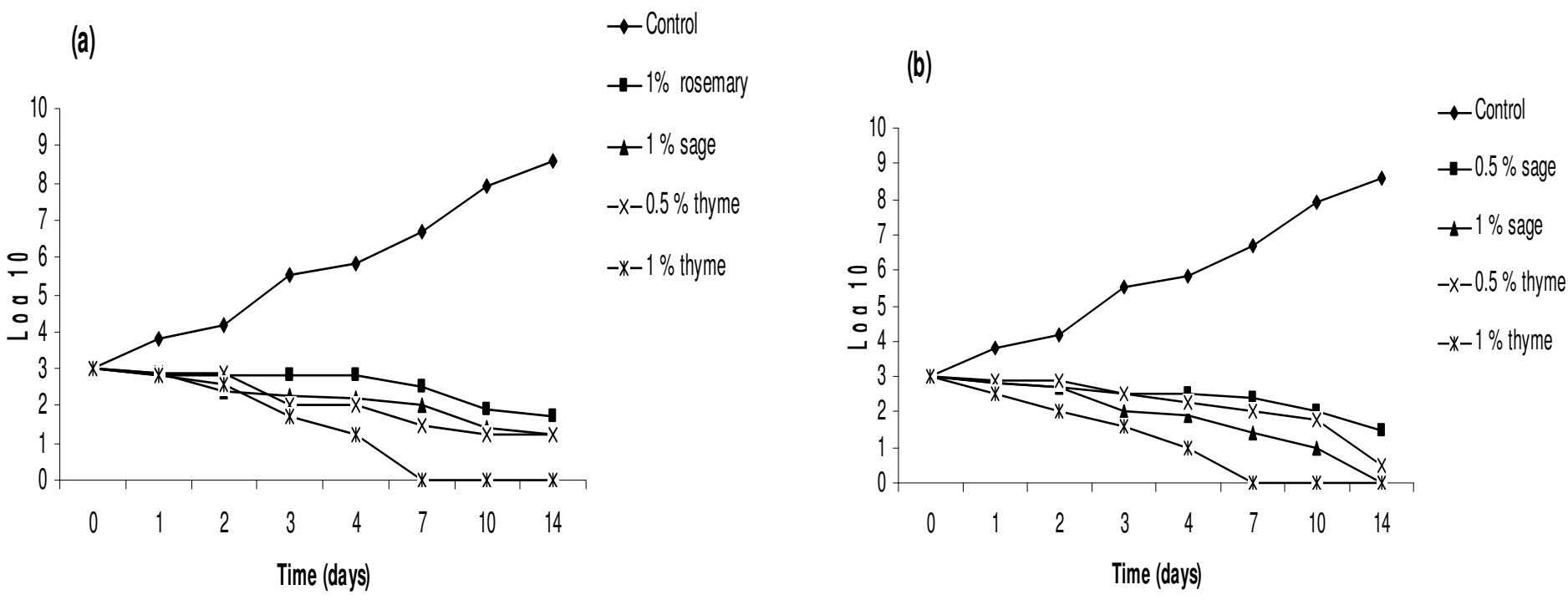

Figure 1. Time-related survival, at $7^{\circ} \mathrm{C}$, of (a) VRE and (b) E. coli $\mathrm{O} 157: \mathrm{H} 7$ following treatment with increasing concentrations of potent EOs, respectively. Bacteria were supplemented in feta cheese samples at $10^{3} \mathrm{CFU} / \mathrm{g}$ of cheese. Values are the average of three individual replicates (means \pm S.D). Differences between samples were determined by Student's t-test and were considered to be significant when $\mathrm{p} \leq 0.05$ at least. 
(a)

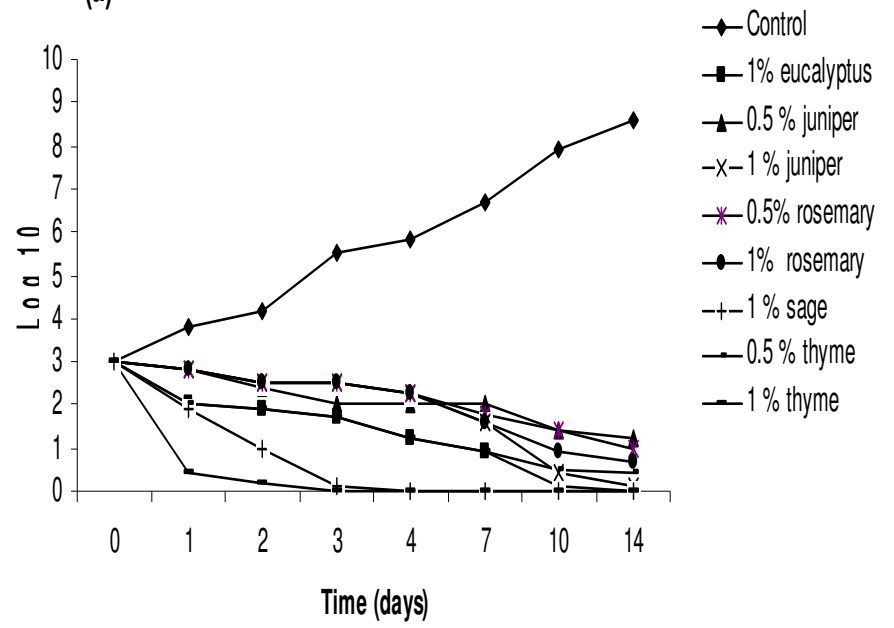

(b)

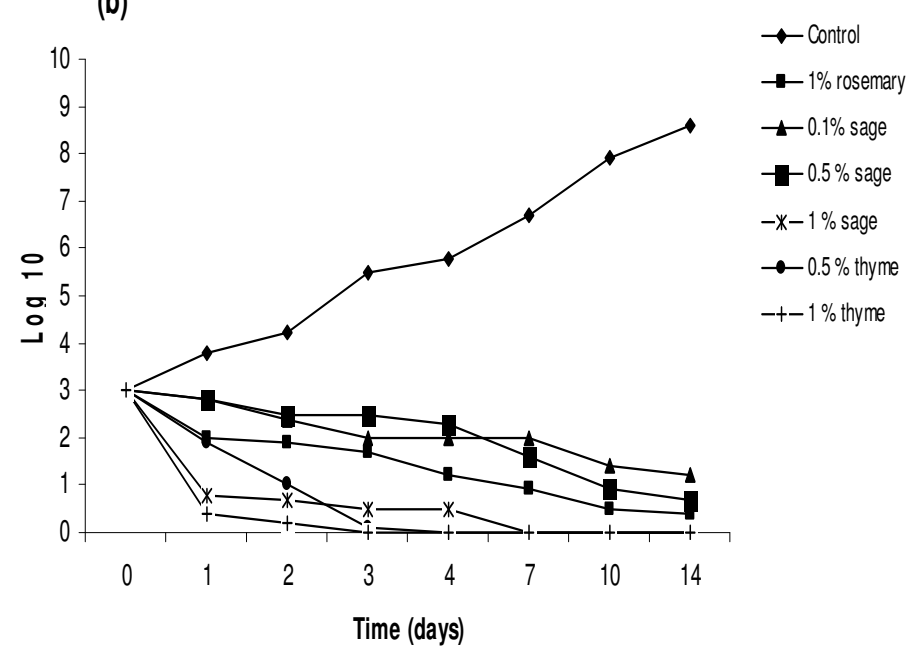

Figure 2. Time-related survival, at $7{ }^{\circ} \mathrm{C}$, of (a) VRE and (b) E. coli $\mathrm{O} 157: \mathrm{H} 7$ following treatment with increasing concentrations of potent EOs, respectively. Bacteria were supplemented in minced beef meat samples at $10^{3} \mathrm{CFU} / \mathrm{g}$ of meat. Values are the average of three individual replicates (means \pm S.D). Differences between samples were determined by Student's t-test and were considered to be significant when $\mathrm{p} \leq 0.05$ at least.

\section{DISCUSSION}

Food contamination is still an enormous public health problem, but may be better controlled by the use of natural preservatives. This study showed that many EO possess an antibacterial activity against VRE and E. coli O157:H7. All of them influence bacterial growth at different concentrations. Among the EOs tested, eucalyptus, juniper, rosemary, sage, clove and thyme were the most active with a smaller MIC on the bacteria tested. Between them, thyme was the most active with a MIC value $0.25-1 \%$ on VRE and $0.25-0.5 \%$ on $E$. coli O157:H7. Also, this study created directly comparable, quantitative, antimicrobial data for oils. As food preservatives, EOs may have their greatest potential use. Spices and herbs, which are used as integral ingredients in prepared foods or added as flavoring agents to food, are present in insufficient quantities for their antimicrobial properties to be significant. On the other hand, volatile oils, which often contain the principal aromatic and flavoring components of herbs and spices, even added in small quantity to foodstuffs, without affecting organoleptic properties, would reduce bacterial contamination. However, also our studies undertaken in food to confirm the antimicrobial efficiency level of these EOs, and their organoleptic impact.

The MICs and MBCs of juniper oil for the VRE strains were, in common with those for the E. coli O157:H7 strains, $2 \%$, a surprising observation in view of the longstanding reputation of this agent as an antiseptic (27). The good in-vitro activities of seven of the eleven EOs evaluated here against VRE and E. coli $\mathrm{O} 157: \mathrm{H7}$ isolates suggest that these agents may have potential for topical use, and clinical trials designed to assess their efficacies in vivo are warranted. Owing to their more pleasant odour and 'greener' image than current topical formulations, EOs may have the added advantage of being more acceptable to patients (23). It is worth remembering, however, that the current practice of incorporating subinhibitory concentrations of oils of medical use in cosmetics may undermine the potential efficacies of these compounds.

Burt (3) found that the antibacterial activity of oregano oil against Salmonella typhimurium was limited by the physical structure of the food. This author also indicates that fats, proteins, water content, antioxidants, preservatives, $\mathrm{pH}$, salt 
and other additives are relevant in the bacterial sensitivity to biopreservatives. The diffusion rate of oil active principles and their low vapor pressures can also limit the microorganisms exposure (26). Smith-Palmer et al. (31) reported that the effectiveness of EOs on L. monocytogenes was affected by cheese composition. Likewise, Canillac and Mourey (6) reported that the introduction of sodium fat into the test medium decreased the bactericidal effects of essential oils. It is generally accepted that high levels of fat and/or protein in foodstuffs protect the bacteria from the action of essential oils. The EOs would be dissolved in the lipid phase of the food and would be less available to act on bacteria that are present in the aqueous phase (22).

Thus, the differences between beef and cheese in structure and composition, and especially in the fat, protein and water contents, could explain the differences in the inhibitory effects of EOs. Two important variables appear when EOs are applied either in vivo or in vitro assays; one is the contact time for oils to exert their effect and the other is the concentration required to achieve the same degree of inhibition, and these two variables would be interacting. The lower water content of foods compared to laboratory media may hamper the progress of antibacterial agents to the target site in the bacteria cell (31). Furthermore, in vitro assays, microorganisms and essential oils come into close contact, but in vivo, the food matrix has cell membranes that act as physical barriers interfering oil and microorganism contact. Moreira et al. (22) reported that in vitro assays, the maximum E. coli $\mathrm{O} 157: \mathrm{H} 7$ reductions $(3.5$ $\log$ ) exerted by thyme oil required 15 min of contact time and that longer contact times did not result in higher E. coli O157:H7 reductions.

It has generally been found that a greater concentration of EOs is needed to achieve the same effect in actual foods than in in vitro assays (21). Moreir et al. (22) reported that greater concentration of EO (approximately two fold) was needed to reach the same effects in semi skimmed milk. The greater availability of nutrients in foods compared to laboratory media may enable bacteria to repair damaged cells faster (14). The oil concentrations required to produce a certain level of inhibition in actual foods could be questionable due to the organoleptic impact. Feta cheese and minced cooked beef treated with higher concentration of clove and tea tree oils presented a strong off-flavor. In this way, the oil concentration required to reach an effective on VRE and E. coli O157:H7 control produced in both food systems undesirables changes in organoleptic characteristics. Synergistic effects would have to be exploited to maximize the antibacterial activity of essential oils and to minimize the concentrations required to achieve a particular antibacterial affect without adversely affecting the sensorial acceptability. A number of potential synergic factors have been suggested for use with essential oils such as reducing $\mathrm{pH}$, adding organic acids, low reducing oxygen tension using modified atmospheres, applying mild heat shocks and so on (3).

Improvements in the shelf-life of product can have an important economic impact by reducing losses attributed to spoilage and by allowing the products to reach distant and new markets. New trends in food preservation lead to a reduction in the levels of preservatives or/and to the use of "naturallyderived" antimicrobials of animal, vegetable, or microbial origin. Among natural vegetable substances, plants and extracts from several types of plants used as flavouring agents are known to possess antimicrobial activity and seem to be suitable for different types of products as sausages, meats and fruit juices. Results concerning EO as natural preservatives seem encouraging since their uses contribute in the reduction and/or in the elimination of experimentally inoculated VRE and $E$. coli $\mathrm{O} 157: \mathrm{H7}$, depending on the concentration used and the initial bacterial load. These conservative effects were enhanced when we combined the use of the EO with refrigerated storage. Nonetheless, this task seems hampered in some extent by some organoleptic attributes, which appear to be responsible for minimizing the degree of acceptance or liking for the product added with high level of the EOs. As described elsewhere, the best solution will be the use of these additives, at lower concentrations, in combination with other natural preservatives or methods. Nonetheless, encapsulation of the EO seems also to be an attractive new approach. In fact, micro encapsulation 
techniques have became popular because they are the most versatile means of over coming problems like those inherent to these of EO as food additives. It is now well established that amongst the basic objectives of micro encapsulation are to reduce material toxicity, provide environmental protection to sensitive compounds and to mask the undesirable taste and aroma of certain compounds $(5,15)$. Thus, the use of hurdle technology could produce safe products without substantial loss of sensory quality.

\section{ACKNOWLEDGEMENTS}

The author likes to thank SAIA, Slovak Academy Information Agency for his support and assistance during this investigation.

\section{REFERENCES}

1. Bruni, R.; Medoco, A.; Andreotti, E.; Fantin, C.; Muzzoli, M.; Dehea, M.; Romagnol, C.; Sacchetti, G. (2004). Chemical composition and biological activities of Ishpingo essential oils, a traditional Ecuadorian spices from Ocotea quixos (Lam.) Kosterm. (Lauraceae) flower calices. Food Chem. 85, 415-421.

2. Buchanan, R.L.; Doyle, M.P; (1997). Foodborne disease significance of Escherichia coli O157:H7 and other enterohemorrhagic E. coli. Food Technology 51, 69-76.

3. Burt, S.A. (2004). Essential oils: Their antibacterial properties and potential applications in foods - a review. Int. J. Food Microbiol. 94, 223-253.

4. Burt, S.A.; Reinders; R.D. (2003). Antibacterial activity of selected plant essential oils against Escherichia coli O157:H7. Letters in Applied Microbiology, 36, 162-167.

5. Bylaité, E; Venskutonis, P.R.; Maždžieriené, R.; (2001). Properties of caraway (Carum carvi L.) essential oil encapsulated into milk proteinbased matrices. European Food Research and Technology 212, 661-670.

6. Canillac, N.; Mourey, A. (2004). Effects of several environmental factors on the anti-Listeria monocytogenes activity of an essential oil of Picea excelsa. Int. J. Food Microbiol. 92(1), 95-103.

7. Careaga, M.; Fernandez, E.; Dorantes, L.; Mota, L.; Jaramillo, M.E.; Hernandez-Sanchez, H. (2003). Antibacterial activity of Capsicum extract against Salmonella typhimurium and Pseudomonas aeruginosa inoculated in raw beef meat. International Journal of Food Microbiology $83,331-335$.

8. Dadalioglu, I.; Everendilek, G. (2004). Chemical composition and antibacterial effects of essential oils of Turkisse oregano, Bay laurel,
Spanish lavender on common food borne pathogens. J. Agric. Food Chem. 52, 8255-8260.

9. Dorman, H.J.D.; Deans, S.G. (2000). Antimicrobial agents from plants: antibacterial activity of plant volatile oils. Journal of Applied Microbiology 88, 308-316.

10. Draughon, A. (2004) .Use of botanicals as biopreservatives in foods. Food Technol. 58(2), 20-28.

11. El-Alfy, S.M.; Selim, S.A.; Abdel Aziz, M.H.; Diab, A.M.; Makharita, R.R.M. (2007). Vancomycin Resistance and Antibiotic Susceptibility of Enterococci Isolated from Food. Egypt. J. of New Microbiology, 6, 244 256.

12. Elgayyar, M.; Draughon, F.A.; Golden, D.A.; Mount, J.R. (2001). Antimicrobial activity of essential oils from plants against selected pathogenic and saprophytic microorganisms. J. Food Prot. 64(7), 10191024.

13. Friedman, M.; Henika, P.R.; Mandrell, R.E. (2002). Bactericidal activities of plant essential oils and some of their isolated constituents against Campylobacter jejuni, Escherichia coli, Listeria monocytogenes and Salmonella enterica. J. Food Prot. 65(10), 1545-1560.

14. Gill, A.; Delaquis, P.; Russo, P.; Holley, R .(2002) .Evaluation of antilisterial action of cilantro oil on vacuum packed ham. Int. J. Food Microbiol. 73, 83-92.

15. Gouin, S. (2004) .Microencapsulation: industrial appraisal of existing technologies and trends. Trends in Food Science \& Technology 15, 330347.

16. Hammer, K.A.; Carson, C.F.; Riley, T.V/ (1999). Antimicrobial activity of essential oils and other plant extracts. Journal of Applied Microbiology $86,985-990$.

17. Jay, J.M. (1992), Modern Food Microbiology. Fourth Edition. NewYork: Chapman and Hall.

18. Joshua, R.; Hayes, J.R.; English, L.L.; Carter, P.J.; Proescholdt, T.; Lee, K.Y. (2003). Prevalence and antimicrobial resistance of Enterococcus species isolated from retail meats. Applied Environmental Microbiology, 7153-7160.

19. Koluman, A.; Akan, L.S.; Cakirog, F.P. (2009). Occurrence and antimicrobial resistance of enterococci in retail foods. Food Control 20, 281-283.

20. Mead, P.S.; Griffin, P.M. (1998). Escherichia coli O157:H7. Lancet 352, 1207-12.

21. Moreira, M.; Ponce, A.; Del Valle, C.; Roura, S. (2005). Inhibitory parameters of essential oils to reduce a foodborne pathogen. Lebensm.Wiss. Technol. 38(5), 565-570.

22. Moreir, M.R.; Ponce, A.G.; Del Valle. C.E.; Roura, S.I. (2007). Effect of clove and tea tree oils on Escherichia coli O157:H7 in Blanched Spinach and minced cooked beef. Journal of Food Processing and Preservation 31, 379-391.

23. Nelson, R.R.S. (1997). In-vitro activities of five plant essential oils against methicillin-resistant Staphylococcus aureus and vancomycinresistant Enterococcus faecium. Journal of Antimicrobial Chemotherapy 
40, 303-309.

24. Oussalah, M.; Caillet, S.; Salmiéri, S.; Saucier, L.; Lacroix, M. (2004). Antimicrobial and antioxidant effects of milk protein-based film containing essential oils for the preservation of whole beef muscle. Journal of Agricultural and Food Chemistry 52, 5598-5605.

25. Oussalah, M.; Caillet, S.; Saucier, L.; Lacroix, M. (2007). Inhibitory effects of selected plant essential oils on the growth of four pathogenic bacteria: E. coli O157:H7, Salmonella Typhimurium, Staphylococcus aureus and Listeria monocytogenes. Food Control 18, 414-420.

26. Ponce, A.; Del Valle, C.; Roura, S (2004). Shelf life of leafy vegetables treated with natural essential oils. J. Food Sci. 69, 50-56.

27. Potterton, D.; Shellard, E.J.; Press, J.R. (1996). Culpeper's Colour Herbal, 2nd edn. Foulsham, London.

28. Roller, S. (2004). Naturals antimicrobials for the minimal processing of foods. Lebensm.-Wiss. Technol. 37, 497-498.
29. Shelef, L.A. (1983) Antimicrobial effects of spices. J. Food Safety 6, 2944.

30. Smith-Palmer, A.; Stewart, J.; Fyfe, L. (1998). Antimicrobial properties of plant essential oils and essences against five important food-borne pathogens. Letters in Food Microbiology 26, 118-122.

31. Smith-Palmer, A.; Stewart, J.; Fyfe, L. (2001). The potential application of plant essential oils as natural food preservatives in soft cheese. Food Microbiology 18, 463-470.

32. Tsegaye, M.; Ephraim, E.; Ashenafi, M. (2004). Behaviour of E. coli O157:H7 during the fermentation of Datta and Awaze, traditional Ethiopian fermented condiments and during products storage at ambient and refrigeration temperatures. Food Microbiol. 21(6), 743-751.

33. Weinbren, M.J.; Johnson, A.P.; Woodford, N. (2000). Defining highlevel gentamicin resistance in enterococci. Journal of Antimicrobial Chemotherapy, 45, 404-405. 